\title{
ANÁLISE DE PROSA ENREDADA NA PESQUISA COM OS COTIDIANOS: UM JEITO DE VER O CURRÍCULO E DIZER
}

Valdriano Ferreira do Nascimento ${ }^{1}$ Isabel Maria de Sabino Farias ${ }^{2}$ Evódio Maurício Oliveira Ramos ${ }^{3}$

\section{INTRODUÇÃO}

A análise dos dados destaca-se entre os desafios que circundam o pesquisador durante o desenvolvimento de uma investigação científica, em particular em iniciativas que adotam uma abordagem qualitativa. Não é incomum que alguns pesquisadores se encontrem com os dados produzidos, mas ainda sem a escolha e a devida clareza do método mais adequado para a realização de sua análise.

Diante desta realidade, a nossa pretensão neste texto é apresentar a Análise de Prosa Enredada (APE) como procedimento alternativo e inovador para analisar dados produzidos em pesquisas com abordagem qualitativa, a exemplo da pesquisa com os cotidianos. Este tipo de pesquisa assume dentre suas principais características, a análise decorrente da problematização da prática, das criações, das invenções e das interpretações das diversas formas de saberesfazeres ${ }^{4}$ cotidianos (CERTEAU, 1994, 1996; FERRAÇO, 2003, 2007, 2016; ALVES, 2002). Este procedimento analítico foi delineado a partir do desenvolvimento de um estudo doutoral que adotou a pesquisa com os cotidianos.

\footnotetext{
${ }^{1}$ Doutorando em Educação da Universidade Estadual do Ceará. É professor efetivo da Universidade Estadual do Ceará (UECE), atuando na Faculdade de Filosofia Dom Aureliano Matos (FAFIDAM).

${ }^{2}$ Doutora em Educação pela Universidade Federal do Ceará (UFC), com estágio pós-doutoral pela UNB. Licenciada em Pedagogia pela Universidade Estadual do Ceará (UECE). Professora associada da UECE, vinculada ao Curso de Pedagogia e ao Programa de Pós-Graduação em Educação (Mestrado e Doutorado).

${ }^{3}$ Doutor em Educação pela Universidade Estadual do Ceará (2018) e Membro Pesquisador do Núcleo de Estudos e Pesquisas sobre Pedagogia Universitária (NEPPU-UEFS) e do Grupo de Pesquisa Educação, Cultura escolar e Sociedade (EDUCAS-UECE). É Professor Assistente com Dedicação Exclusiva do Departamento de Saúde - DSAU/ Universidade Estadual de Feira de Santana.

${ }^{4}$ Os termos grafados juntos e em itálico que aparecem neste texto surgem da ideia de Alves (2017), no entendimento de que as dicotomias criadas do pensamento científico da modernidade, apresentam limites, naquilo que as pesquisas com os cotidianos buscam compreender.
} 
Para efeito deste escrito, retomamos esta investigação para situar a emergência da Análise de Prosa Enredada, bem como os caminhos percorricos em todo o processo de sua constituição, destacando as possibilidade do seu uso e de seu potencial para favorecer a leitura reflexiva das experiências vividas, a interpretação crítica de narrativas e a compreensão do mundo vivido.

\section{ANÁLISE DE PROSA ENREDADA: ELABORAÇÃO E FINALIDADE}

A pesquisa com os cotidianos, fundamentada na perspectiva de Michel de Certeau (1994, 1996), defende a ideia que demonstra ser consistente, de que as pesquisas "com" os cotidianos, relacionam-se diretamente com as dimensões "do lugar", "do habitado", “do vivido", "do praticado" e "do usado". Para Certeau (1996, p. 31), “[...] O cotidiano é aquilo que nos prende intimamente, a partir do interior. É uma história a meio-caminho de nós mesmos, quase em retirada, às vezes velada [...]. O que interessa ao historiador do cotidiano é o invisível [...] não tão invisível assim”. Imbuído por esse mesmo ideário, Ferraço (2016, p. 29) assume a posição de que,

[...] qualquer tentativa de pesquisa com os cotidianos só se sustenta enquanto possibilidade de algo pertinente, algo que tem sentido para a vida cotidiana, se acontece com as pessoas que praticam esses cotidianos e, sobretudo, também a partir das questões/temas que se colocam como pertinentes às redes cotidianas. Posto isso, precisamos considerar, então, que os sujeitos cotidianos, mais do que objetos de nossas análise são, de fato, também protagonistas, também autores coletivos de nossas pesquisas.

Dito isto, compreendemos que o estudo do currículo produzido nos cotidianos da formação do pedagogo deve ocorrer em meio às situações do dia a dia através das experiências vividas pelos sujeitos da ação. Postura esta, que se aproxima do conceito de currículo proposto por Sacristán, ao afirmar que,

[...] Na situação escolar se aprendem mais coisas, dependendo da experiência de interação entre alunos e professores, ou entre os próprios (...) Por isso se diz que o currículo real, na prática, é a consequência de se viver uma experiência em um ambiente prolongado que propõem - impõem - todo um sistema de comportamento e de valores, e não apenas de conteúdos de conhecimentos, a assimilar. Esta é a razão pela qual aquele primeiro significado de currículo como documento ou plano explicito se desloca para um outro, que considere a experiência real do aluno na situação de escolarização (1995, p. 86).

Corroborando com essa visão, entendemos que para a problematização e compreensão do currículo produzido e vivenciado na formação do pedagogo, sendo tecido em meio às experiências vividas, é necessário uma implicação com os sujeitos envolvidos no seu cotidiano, incluindo além da 
compreensão dos conteúdos formais, comumente estudados, as questões de currículo produzidas nas relações estabelecidas por esses sujeitos, com seus anseios e perspectivas aflorados no contexto da ação. "Os currículos praticados são processos cotidianos intrinsecamente enredados, que se determinam mutuamente, não havendo como diferenciá-los, pensá-los de forma isolada, em meio às tessituras e partilhas das redes cotidianas de saberes/fazeres" (FERRAÇO, 2007, p. 76).

Assim, assumimos essa perspectiva teórico metodológica de pesquisa na tentativa de compreender o currículo produzido nas práticas cotidianas, apostando nos atos da vida cotidiana, meio as narrativas e depoimentos das professoras e alunos participantes da pesquisa, partilhando com esses sujeitos sociais dos seus ideários e das suas práticas vividas, seguindo as "veredas" que possam ser percebidas, sentidas e trilhadas nos contextos de tessitura do currículoformação do pedagogo na instituição e na realidade que se insere.

Dessa forma, entendemos que a pesquisa com os cotidianos assume caráter qualitativo por se caracterizar pela descrição e interpretação dos dados a partir dos pontos de vista dos sujeitos estudados sobre suas vivências, e considerando a própria experiência do pesquisador como base para a realização da pesquisa.

A vida cotidiana é um espaço da vida natural, ou seja, um espaço onde as pessoas estabelecem relações com os fenômenos aos quais a intencionalidade pode alcançar e dar significados. Significados esses produzidos pelos sujeitos em suas tramas sociais permeadas pela diversidade, tensões e contigenciamentos coletivos e pelas idiossincrasias elaboradas a partir do vivido e do experimentado. Isto pode possibilitar, nas pesquisas qualitativas, a busca por "novos instrumentais científicos que permitam acompanhar a complexidade e a processualidade das formas de subjetivação, tais como se apresentam na atualidade" (PAULON; ROMAGNOLI, 2010, p. 87).

Tendo como temática de investigação "o currículo em ação na formação do pedagogo", a pesquisa com os cotidianos realizada em contextos da formação do pedagogo na Universidade Estadual do Ceará (UECE), no período de 2018 a 2019, adequou-se ao estudo por se tratar de uma perspectiva metodológica crítica, que busca compreender os fenômenos que ocorrem através da interação dos sujeitos nos locais onde se desenvolve o conhecimento.

Assim, diante do nosso posicionamento em favor da abordagem estritamente qualitativa, tendo como pano de fundo a pesquisa com os cotidianos, deparamo-nos com as primeiras experiências e produção de dados do currículo produzido nas veredas da prática de formação do pedagogo, as quais nos levaram à seguinte indagação: qual a técnica ou procedimento mais adequado para a análise dos dados do currículo, em produção, que possa dar conta de interpretar e retratar com qualidade o mundo vivido pelos praticantes da pesquisa? Com isto, ao assumirmos como tema deste 
estudo um procedimento de análise de dados adequado às pesquisa com/os/dos cotidianos, buscamos na literatura existente, identificar métodos e técnicas de análise de dados alinhados à pesquisas qualitativa para pensarmos um procedimento de análise de dados caracterizado pela inventividade das diversas maneiras de ver a temática em estudo, anilisar e compreender.

Com esse intento, ao fazer a leitura de alguns métodos e técnicas de análise de dados, não encontramos nenhum que pudesse dar conta do estudo em andamento, no sentido de problematizar, interpretar, apreender e compreender as práticas cotidianas nos contextos da pesquisa a contento. Entendendo também como Ferraço (2003, p. 162) que uma "metodologia de análise a priori nega a possibilidade do com, do fazer junto", tentamos reelaborar um procedimento de análise, seguindo um percurso próprio, com o nosso jeito de fazer, interpretar e dizer, mas que pudesse contribuir na percepção de elementos curriculares embutidos no emaranhado dos dados presentes nos instrumentos de produção do currículo cotidiano, fluídos das diversas vozes dos praticantes. Nos apegamos ainda a Certeau (1996), ao considerar que ainda inexistem instrumentos de pesquisa e análises de dados que consigam contribuir para a percepção e apreensão, com abundância, das práticas cotidianas.

Nossas categorias de saber ainda são muito rústicas e nossos modelos de análise por demais elaborados para permitir-nos imaginar a incrível abundância inventiva das práticas cotidianas. É lastimável constatá-lo: quanto nos falta ainda compreender dos inúmeros artifícios dos "obscuros heróis" do efềmero, andarilhos da cidade, moradores dos bairros, leitores e sonhadores, pessoas obscuras das cozinhas (CERTEAU, 1996, p. 342).

Assim sendo, após um extenso processo de levantamento bibliográfico, mais especificamente, em busca realizada na Biblioteca Digital Brasileira de Teses e Dissertações (BDTD), encontramos a “Análise de Prosa”, proposta por André (1983), que apresenta fortes características do procedimento de análise de dados que procurávamos.

Ao fazer o levantamento das teses de doutoramento em educação, das duas últimas décadas, só encontramos três teses em que os autores fizeram opção pela técnica de análise de prosa, pautada na proposta de André (1983). São elas: a tese de Rodnei Pereira (2017), do Programa de Pósgraduação em Educação da PUC-SP, orientada pela professora Vera de Souza Placco; a tese de Gláucia Signorelli de Queiroz Gonçalves (2016), da PUC-SP, orientada pela própria professora pesquisadora Marli André; e a tese de Maria de Fátima Jeronimo Marques (2018), do Programa de Pós-Graduação em Educação da Universidade Federal do Rio Grande do Norte, orientada pela professora Rita de Cassia Barbosa Paiva Magalhães. 
Pereira (2017), em sua tese, não detalha como realizou o exame dos dados na perspectiva da análise de prosa, apenas afirma que se inspirou nessa proposta de André (1983), apresentando uma única citação em que a professora Marli André se refere à análise de prosa como:

[...] uma forma de investigação do significado dos dados qualificativos. É um meio de levantar questões sobre o conteúdo de um determinado material: o que é que este diz? $\mathrm{O}$ que significa? Quais suas mensagens? E isso incluiria, naturalmente, mensagens intencionais e não-intencionais, explícitas ou implícitas, verbais ou não verbais, alternativas ou contraditórias (ANDRÉ, 1983, p. 67).

Nessa citação, a autora caracteriza a análise de prosa pelo significado atribuído aos dados, na tentativa de responder as questões e objetivos levantados, através da interpretação das mensagens intencionais ou não, explícitas ou nas entrelinhas, apresentadas meio a quaisquer procedimentos de produção de dados, sejam eles verbais ou não verbais.

Já na tese de Gláucia Gonçalves (2016), ela afirma ter adotado o método denominado de análise de prosa por André (1983), buscando sustentação na mesma citação apresenta na tese de Pereira (2017).

Por último, Maria de Fátima Marques (2019) afirma ter utilizado apenas para fins de interpretação dos dados o que André (1983) considera como análise de prosa, apresentando a citação em que a autora diz: "análise de prosa é considerada uma forma de investigação do significado dos dados qualitativos. É um meio de levantar questões sobre o conteúdo de um determinado material” (ANDRE, 1983, p. 67).

Diante das perspectivas de utilização desse método pelos pesquisadores acima mencionados, ao fazermos opção pelo uso da terminologia do procedimento mencionado, ou seja, um jeito, uma maneira de fazerfalar os dados produzidos, percebemos que, para além da analise de prosa, estávamos realizando a Análise de Prosa Enredada, que foi se desenvolvendo por intermédio da várias ações, desde a escuta das vozes de todos os praticantes até a escrita do texto enredado, carregado de nossas impressões e sentidos dados às mensagens e às observações das experiências vividas nos contextos de produção dos dados.

Surge desse ponto, nossa propositiva em acrescentar, na definição da análise que realizamos, os sentidos dados às vozes dos praticantes, constituídos, também, no momento da produção do texto enredado. Os pesquisadores/autores, além de olhar para os dados, estavam pensando e refletindo sobre os diversos momentos vividos na interação com os praticantes, na dinâmica de produção dos 
dados por meio dos procedimentos diversos, e ainda com a preocupação de entrelaçá-los, na tentativa de interpretar e registrar as experiências vividas, considerando as afirmativas e observações que corroborariam para a existência das práticas efetivadas, que ao serem confrontadas, permitiam a divergencia e a indicação da existência de outras práticas, ainda presentes no cotidiano das ações dos sujeitos praticantes.

A partir dessa perspectiva, almejamos ao utilizar a análise qualitativa em enredo, ir além, buscando aproximação com a forma de análise proposta por André (1983), por comungar com a finalidade de compreender os sentidos do currículo produzido na vivência dos currículos praticados, mas tendo possibilidade de interpretar e sintetizar as narrativas dos praticantes da pesquisa sobre este fenômeno, considerando as relações, ligações e interseções em torno do fenômeno ou tema estudado, teorizando a recontextualização dos elementos apontados pelos participantes e promovendo a sistematização de novos saberes, sempre estabelecendo um diálogo com outros pesquisadores que discorrem sobre a temática em estudo. Para André (1983), a Análise de Prosa pode ser definida como

Uma forma de investigação do significado dos dados qualitativos onde tópicos e temas vão sendo gerados a partir do exame dos dados e sua contextualização no estudo, sendo preciso que estes tópicos e temas sejam frequentemente vistos, questionados e reformulados, na medida em que a análise se desenvolve, tendo em vista os princípios teóricos e os pressupostos da investigação (ANDRÉ, 1983, p. 57).

Com esse entendimento, a análise realizada ocorreu durante a investigação como um todo, concomitante com o período de produção dos dados, sendo influenciada pelas formas como os dados foram surgindo. Lüdke e André (1986, p. 45) afirmam que “A análise está presente em vários estágios da investigação, tornando-se mais sistemática e mais formal após o encerramento da coleta de dados". Nesses termos, todas as nossas escolhas em relação aos instrumentos, procedimentos e suas formas de realização tiveram consequências diretas à análise dos dados, iniciado junto ao processo de produção dos dados.

Nesse sentido, dizemos que a análise reelaborada e aplicada em nossa pesquisa, mesmo se aproximando da Análise de Prosa proposta por André (1983), transcendeu às definições e características dessa perspectiva de análise. A forma de interagir com os praticantes ${ }^{5}$ da pesquisa, o olhar para os dados, o procedimento de triangulação, nossas percepções, nossas experiências vividas

\footnotetext{
${ }^{5}$ Termo utilizado a partir da nossa compreensão do protagonismo dos sujeitos participantes da pesquisa enquanto atores que vivenciam e praticam tambem o ato de pesquisar, mesmo sendo os próprios sujeitos dessa análise.
} 
e registradas, os sentidos e a compreensão dos dados no diálogo com outros autores e, principalmente, na forma de produção, análise e apresentação dos dados, no enredamento dos resultados proferidos nos diversos procedimentos de produção dos dados, fez com que se processasse um novo método de análise, para além da análise de prosa. Procedimento de análise que se aproxima, também, das ideias de Ferraço (2001), ao criar um jeito próprio de fazer, compreender e registrar tudo que foi realizado e a forma como se fez.

A triangulação dos dados por nós realizada se aproxima do protocolo denominado por Stake (2016), de "triangulação das fontes de dados", com a finalidade de verificar se as narrativas proferidas em determinado instrumento de produção dos dados se repetiam ou eram semelhantes em outros, ou ainda, se eram relatados de forma diferente, e se isto se confirmava nas observações dos participantes. Ao aparecer narrativas e/ou práticas em sala de aula diferentes daquelas proferidas em outros momentos de produção dos dados, mas que eram merecedoras de análise por conferir sentido para a compreensão do tema em estudo, essas também, foram levadas em consideração. Desse modo, “A triangulação das fontes de dados é um esforço para ver se o que estamos a observar e a relatar transmite o mesmo significado quando descoberto em circunstâncias diferentes" (STAKE, 2016, p. 126).

A análise de prosa enredada realizada com auxílio da triangulação de fontes permitiu o confrontamento dos dados, chegando à percepção de elementos curriculares semelhantes aos contextos estudados, mas também constando a presença de elementos distintos, específicos de cada contexto.

O enredamento ocorreu desde a produção do texto de fundamentação teórica, fazendo um breve histórico sobre a produção do currículoformação do pedagogo no Brasil, tentando o tempo todo trazer para o enredo as concepções de currículo presentes nos diversos períodos de avanços e retrocessos na formação desde profissional, considerando também as perspectivas dos autores que teorizaram sobre a temática em estudo.

$\mathrm{Na}$ análise dos dados produzidos pelos praticantes da pesquisa, o enredo se deu com a triangulação, confrontando e comparando narrativas diversas com as observações da prática docente das professoras, em cada contexto da pesquisa, sendo levados para a produção do texto de análise, também enredado, apoiado nas diversas narrativas e registros de observações, advindos dos diferentes procedimentos de produção dos dados para uma análise que foi realizada mediante diálogo com os principais autores que serviram de base na elaboração do texto de fundamentação teórica. 
O enredamento ocorreu também na produção do texto de análise dos resultados, dos elementos curriculares comuns e/ou semelhantes, obtidos nas intercessões dos contextos da pesquisa, bem como aqueles diferentes, singulares em cada contexto, analisados e registrados anteriormente e revisitados durante a produção do texto com a finalidade de compreensão da temática em estudo como um todo.

Considerando o que preceitua Joly Gouveia (1984), de que a experiência do pesquisador, com a literatura pertinente e as diferentes formas de analisar os dados de pesquisa com abordagem qualitativa, é condição necessária para que se realize um estudo adequado e produza um conhecimento novo, levando em conta que o pesquisador é, na realidade, o seu próprio instrumento de trabalho, e, ainda, destacando a forma de análise e produção do texto com os resultados que implicam na compreensão da temática em estudo, ousamos em denominar o procedimento de análise de dados que realizamos de Análise de Prosa Enredada.

Esta análise qualitativa de dados, além de se caracterizar por um processo indutivo de interpretação de narrativas inseridas nos diversos procedimentos de produção dos dados, com foco na fidelidade das informações percebidas do universo de vida cotidiana dos sujeitos praticantes, caracteriza-se, também, pelo enredamento do texto, apresentando as narrativas, relatos e/ou depoimentos, que aparecem na organização, interpretação e sentidos dados a cada tema ou subtema em análise, num confrontamento e diálogo permanente com os autores, possibilitando a realização da síntese que implica em um fazersaber novo.

Unimo-nos a André (1983), no sentido de dizer que a análise de prosa, aqui acrescentada por nós, do enredo, visa apreender o caráter multidimensional dos fenômenos em sua manifestação natural, bem como captar os diferentes sentidos de uma experiência vivida, auxiliando na compreensão dos saberesfazeres do indivíduo no seu contexto, acompanhado dos seus significados. Aqui, queremos acrescentar, também, os registros das diversas formas de fazer, inseridos na produção enredada do texto, carregados dos sentidos dados para essas práticas vividas pelos pesquisadores/autores da produção textual que fecunda e nasce desse processo de pesquisa.

\section{A BUSCA DE INTERPRETAÇÃO E COMPREENSÃO DE DIFERENTES NARRATIVAS NO PERCURSO DE ANÁLISE}

A pesquisa foi desenvolvida em diferentes campi de produção do currículoformação do pedagogo na UECE. Os sujeitos praticantes da pesquisa foram as professoras e licenciandos dos cursos de Pedagogia dessa instituição, em três campi, sendo para cada contexto, as professoras que estavam atuando na disciplina de Didática, acompanhados de seus licenciandos que tinham, no início 
da produção do dados, pelo menos 01 ano de experiência de prática docente no contexto da escola básica.

Todos os dados produzidos no decorrer da realização dos diversos procedimentos junto aos praticantes da pesquisa em torno do currículoformação do pedagogo na instituição pesquisada, tais como: narrativas escritas, registros de entrevista, depoimentos resultantes dos grupos de conversa e o relato das experiências vividas durante as observações participantes em sala de aula, foram transcritos em arquivos distintos, relidos, organizados e separados por temas e subtemas, gerando novos arquivos com as narrativas e/ou relatos das conversas, fragmentos das entrevistas e registros de observações, que trataram do mesmo tema para serem material da análise qualitativa. A esse movimento, Alves (2003), denominou de beber em todas as fontes.

Fizemos a opção por analisar os dados produzidos a partir de aspectos que permitiram compreender os sentidos da realidade estudada, estritamente qualitativos, objetivando conclusões provisórias e teorizações do conhecimento novo, de forma que pudesse possibilitar novas explicações e interpretações no entendimento do estudo, em busca do alcance dos objetivos desejados (LUDKE; ANDRÉ, 1986).

No decorrer da análise que realizamos, foi possível identificar, por meio do procedimento de triangulação, mensagens e observações contraditórias, em que um praticante apresentou relatos da existência de determinadas práticas diferentes da forma como outros praticantes disseram que elas ocorrem. Foram emitidas, também, mensagens por praticante, em que ele mesmo, entrou em contradição, sobre algumas práticas vividas, afirmando, por exemplo, na entrevista, que realizava uma prática de uma forma e, na narrativa apresentava outra, sendo constatado durante as observações, práticas não apontadas por ele no diálogo de produção dos dados. Isto também nos fez compreender a necessidade de confrontar informações para fazer as considerações devidas na produção enredada do texto. Ressaltamos que o processo de análise só termina quando o texto em forma de relatório da pesquisa, chega ao seu final com a construção das considerações finais, ainda que provisórias.

Com isso, o processo de realização da análise se deu a partir da produção e escuta dos primeiros dados, com os temas e subtemas elencados e aqueles que foram surgindo conforme o aparecimento de novas mensagens proferidas no diálogo com os praticantes, percebidas durante a produção e leitura do material. Por exemplo, nos instrumentos construídos para a condução dos procedimentos de produção dos dados não havia em nenhum deles a previsão de indagar sobre a forma como as professoras realizavam a avaliação da aprendizagem dos alunos no contexto da formação e logo na primeira narrativa produzida por uma professora ela relatou as práticas de 
avaliação que realizava. Depois os alunos citaram essas práticas avaliativas, surgindo a necessidade de indagação sobre a forma como esse elemento curricular pedagógico ocorria nos outros contextos de produção dos dados, emergindo um novo subtema analisado.

O que nos inspirou a optar por trabalhar com temas e subtemas e não com categorias foi a alternativa proposta por André (1983), na perspectiva de ampliação da forma de ver, sentir, interpretar e compreender o tema em estudo, tentando fugir da rigidez positivista que ainda perdura nas pesquisas em educação. "Em lugar de um sistema pré-especificado de categorias, eu sugiro que tópicos e temas vão sendo gerados a partir do exame dos dados e de sua contextualização no estudo" (ANDRÉ, 1983, p. 67).

Dessa forma, após a produção dos dados por meio dos instrumentos escolhidos e construídos, e dos procedimentos realizados, demos continuidade ao processo de análise de forma mais sistematizada e consistente, começando pela escuta das gravações em áudio. Em seguida, realizamos a transcrição de todos os dados, em arquivos separados por campi onde os dados foram produzidos.

Ao fazer a leitura do material transcrito, por mais de uma vez, fomos retirando de cada arquivo, decorrente de cada procedimento de produção dos dados, as mensagens que correspondiam a um determinado tema foram colocadas em um outro arquivo, separadas por temas, acompanhadas de seus subtemas, tanto os elementos curriculares identificados e escolhidos ainda na produção dos dados, quanto aqueles que foram surgindo na dinâmica de leitura do material.

Esta atividade artesanal e árdua deu origem à elaboração de um quadro amostral, que continham os temas e subtemas delineados a partir do conteúdo das entrevistas, das narrativas escritas, dos grupos de conversa e o do registro das observações participantes de cada contexto, como é apresentado no quadro a seguir.

Temas e subtemas que correspondem aos dados apresentados e analisados por contexto de investigação

\begin{tabular}{|l|l|}
\hline \multicolumn{1}{|c|}{ TEMAS } & \multicolumn{1}{c|}{ SUBTEMAS } \\
\hline 1. CURRÍCULO & \multicolumn{1}{c|}{$\begin{array}{c}\text { Concepções de currículo das } \\
\text { professoras formadoras } \\
1.2 \text { perspectivas de produção para o } \\
\text { currículoformação do pedagogo na instituição } \\
\text { pesquisa }\end{array}$} \\
\hline $\begin{array}{l}\text { 2. FORMAÇÃO DAS PROFESSORAS } \\
\text { FORMADORAS }\end{array}$ & $\begin{array}{c}\text { 2.1. Experiências da formação inicial } \\
\text { que serviram de base para a constituição dos } \\
\text { saberes das professoras. }\end{array}$ \\
\hline
\end{tabular}




\begin{tabular}{|c|c|}
\hline 3. O CURRÍCULO PRATICADO & $\begin{array}{l}\text { 3.1 Os elementos curriculares } \\
\text { pedagógicos: planejamento, prática pedagógica } \\
\text { e avaliação, praticados na produção do } \\
\text { currículoformação do pedagogo }\end{array}$ \\
\hline $\begin{array}{l}\text { 4. DESAFIOS E POSSIBILIDADES DA } \\
\text { FORMAÇÃO }\end{array}$ & $\begin{array}{l}\text { 4.1 Dificuldades enfrentadas na } \\
\text { produção do currículoformação do pedagogo na } \\
\text { instituição pesquisa } \\
4.2 \text { Sugestões de práticas curriculares } \\
\text { que contribuam com a melhoria da formação do } \\
\text { pedagogo na instituição pesquisa }\end{array}$ \\
\hline
\end{tabular}

Fonte: Elaborado pelos autores.

É importante mencionar que os temas e subtemas apresentados no quadro acima tratam-se de temas que surgiram logo na elaboração projeto de pesquisa, a exemplo do tema currículo, como também os temas e subtemas que surgiram no decorrer do processo de produção e análise dos dados. Por exemplo, ao fazer a leitura das narrativas nos diversos instrumentos de produção dos dados, conforme os relatos apresentados pelas professoras, sentimos a necessidade de analisar o tema currículo, dividindo-o em dois subtemas: o primeiro, concepções de currículo das professoras formadoras, visando analisar as concepções das praticantes sobre o currículo de um modo geral; para, em seguida, analisar o segundo, perspectivas de produção para o currículoformação do pedagogo na instituição pesquisa, no intuito de compreender o que pensam as professoras sobre a produção do currículo de formação do pedagogo, sob sua responsabilidade na instituição em que atuam.

Considerando as proposições de Lüdke e André (1986, p. 45), realizamos o trabalho com “[...] todo o material obtido durante a pesquisa, ou seja, os relatos das observações, as transcrições de entrevistas, as análises de documentos e as demais informações disponíveis" visando uma análise qualitativa aprofundada, contando com a contribuição dos autores “convidados" para o diálogo, a fim de compreender o currículoformação produzido nos contextos da pesquisa.

Com o exercício de ler e reler as narrativas dos praticantes, confrontamos conteúdos citados por alunos e pela professora e as notas do diário de campo, contando com nossas experiências como professores e pesquisadores e, ainda, com o pensamento dos autores que participaram do diálogo desde o início do estudo. Dessa forma, foi possível mapear as práticas de produção do currículoformação do pedagogo nos contextos da pesquisa e a interpretação das experiências vividas no emaranhado das práticas pedagógicas em cada contexto, implicando na construção de novo saber, o qual carrega consigo o registro de fatos e acontecimentos, meio a uma produção textual enredada, coerentes com a realidade vivenciada. Trata-se de um movimento de pensar e criar uma nova maneira 
de escrever para anunciar ao leitor, principalmente, aos praticantes do cotidiano, o que estamos produzindo e refletindo com eles, em suas práticas, vivências e experiências, movimento este, denominado por Alves (2003) em narrar a vida e literaturizar a ciência.

Nessa perspectiva, os dados produzidos foram apresentados em um primeiro texto acompanhados das devidas análises e separados por contexto de investigação, permitindo o mapeamento do currículoformação do pedagogo em cada contexto, perseguindo os mesmos temas e subtemas, tanto os elencados quanto aqueles que surgiram no movimento de escuta, leituras e releituras das vozes dos praticantes, para poder, no texto seguinte, confrontar os dados obtidos e analisados de um contexto para o outro na tentativa de responder a questão central do estudo.

Guiados pelo desejo em responder a pergunta central do estudo, continuamos a análise com a construção do segudo texto, voltando aos dados e fazendo a confrontação devida, subsidiando a elaboração da tese defendida ao final do estudo. Para André (1983, p. 67) “É preciso também que esses tópicos e temas sejam frequentemente revistos, questionados, reformulados na medida em que a análise se desenvolve, tendo em vista os princípios teóricos e os pressupostos da investigação". Assim, retomamos às sínteses dos temas e subtemas, de cada contexto em que os dados foram produzidos e analisados na texto enredado anterior, para analisar e registrar a compreensão do estudo, na tentativa de responder a pergunta central.

\section{OS SENTIDOS PRODUZIDOS NA ANÁLISE DE PROSA ENREDADA PARA A COMPREENSÃO DO FENÔMENO EM ESTUDO}

Diante da pretensão deste artigo, em apresentar a análise de prosa enredada como procedimento de análise de dados meio às pesquisas com abordagem qualitativa, a exemplo da pesquisa com os cotidianos, procuramos explicar o processo pelo qual surgiu a necessidade de reinventar um método de análise de dados, em busca de criar um jeito próprio de acompanhar, interpretar e analisar falas de sujeitos praticantes da pesquisa proferidas através de narrativas diversas. Em seguida, dar clareza de sua finalidade, acompanhado das veredas percorridas, com todas escolhas e os passos trilhados para analisar as perspectivas e o mundo vivido pelos praticantes no processo de produção de currículos praticados no cotidiano da formação do pedagogo em diferentes contexto, problematizando, com ênfase nos aspectos curriculares vividos na prática docente no processo formativo e elementos curriculares praticados nesses contextos, que pudessem dar sentido a formação do profissional pedagogo nessa instituição.

A análise de prosa enredada foi surgindo como um novo procedimento de análise de dados, durante a trajetória pelas veredas da pesquisa, no exercício contínuo de produção e análise dos dados, 
em que fomos aprendendo com o próprio jeito de caminhar a olhar, ouvir e sentir os elementos curriculares que pudessem dar sentido a compreensão do tema em estudo rumo a descrição da realidade com a finalidade de retratar com fidelidade a perspectiva dos praticantes da pesquisa. Movimento que, aos poucos, foi evidenciando a presença de elementos curriculares envolvidos na produção do currículoformação do pedagogo, que acabaram por configurá-los inseridos na perspectiva de currículo vivido e criado nas veredas da prática (CERTEAU, 1994), considerando os processos de inventividade tecidos e experimentados na complexidade (MORIN, 2007) das redes dos saberesfazeres cotidianos (ALVES, 2002; FERRAÇO, 2003, 2007, 2016).

Nesse sentido, a aproximação e a convivência durante a produção dos dados junto aos praticantes da pesquisa nos possibilitou ver, sentir e compreender, com clareza, a criação dos elementos curriculares envolvidos na produção complexa do currículoformação do pedagogo, estabelecidos pelas relações entre os praticantes de cada contexto pesquisado e pelas relações que se processam de um contexto para outro, produzidos na complexidade que dão sentido ao perfil de formaçãoprofissional pensado para uma atuação que dê conta dos anseios que emergem da problemática da prática social atual.

A análise de prosa enredada realizada com auxílio da triangulação de fontes permitiu o confrontamento dos dados, chegando à percepção de elementos curriculares semelhantes aos contextos investigados, mas também constando a presença de elementos distintos, específicos de cada contexto.

Essas práticas específicas identificadas na diversidade dos contextos pesquisados também servem de reflexão e análise em torno das ações de planejamento da formação do profissional da educação como resistência ao atual contexto educacional e profissional, marcado pelas diversas formas de controle e padronização curricular, no intuito de propor, criar na inventividade do processo formativo práticas de fazerespensares coletivas direcionadas para o rompimento e transformação de políticas e projetos educacionais, em execução, de um sistema educacional atual em crise, no caso do Brasil. (CERTEAU, 1995).

Com a realização da análise de prosa enredada dos dados produzidos na caminhada pelas veredas da prática, conseguimos perceber elementos curriculares no âmbito das ações específicas dos diferentes contextos da pesquisa, com rastros que deixam pistas, que evidenciaram a compreensão do tema em estudo, uma vez que as experiências vividas nesses contextos se desenvolvem com base na perspectiva de criação e invenção do saber, considerando a realidade e permitindo a compreensão da capacidade de formar o profissional da educação, como um sujeito de possibilidades, preparado para 
a ação em realidades diversas e de difíceis condições de atuação, mas com resiliência para reunir as forças necessárias, internamente e na relação entre os profissionais das instituições formativas, visando uma prática marcada por mudanças e inovações tanto no contexto local quanto global.

Dentro dessa perspectiva, sugirimos, com base nos desafios enfrentados nos procedimentos de análise de dados e nos inspirando na análise de prosa proposta por André (1983), a análise de prosa enredada. O procedimento de análise de dados reelaborado e apropriado as pesquisas de natureza estritamente qualitativa objetivam colocar à disposição dos pesquisadores qualitativos, mais um procedimento de análise de dados, reinventado, no próprio movimento da pesquisa, emergindo da necessidade do contexto, como procedimento metodológico de análise de dados, facilitador da percepção, interpretação e análise de narrativas de participantes de pesquisa e registros de experiências e observações participantes, na perspectiva do fortalecimento de propositivas direcionadas para a compreensão da formação de profissionais da educação, articulada a criação de 'espaçostempos' de estudo e de práticas que permitam a discussão e troca de experiências vividas, explicitadas pelos sujeitos, envolvidos no processo formativo, através de suas narrativas, proferidas no movimento e na dinâmica de produção do currículoformação, com todos os elementos curriculares envolvidos no processo formativo.

\section{REFERÊNCIAS}

ALVES, Nilda. (Org.). Criar currículo no cotidiano. São Paulo: Cortez, 2002. (SérieCultura, Memória e Currículo, v.1). . Sobre movimentos das pesquisas nos/dos/com os cotidianos. TEIAS: Rio de Janeiro, ano 4, no 7-8, jan/dez 2003. Disponível em: <file:///C:/Users/usuario/Downloads/23967-76799-1-PB.pdf> . Acesso em: 17 abr. 2018.

ANDRÉ, Marli Eliza Dalmazo Adonso de. Texto, contexto e significado: algumas questões na análise de dados qualitativos. Cadernos de Pesquisa, [S.1.], v.45, p.66-71, maio 1983. Disponível em: <http://publicacoes.fcc.org.br/ojs/index.php/cp/article/view/1491>. Acesso em: 05 nov. 2018.

CERTEAU, Michel de. A invenção do cotidiano 1: as artes de Fazer. Petrópolis: Vozes, 1994.

. A invenção do cotidiano 2: morar, cozinhar. Petrópolis: Vozes, 1996.

A revolução do crível. In: . A cultura no plural. Campinas: Papiros, 1995. p.23-40.

FERRAÇO, Carlos Eduardo. Eu caçador de mim. In: GARCIA, R. L. (org.). Método: pesquisa com o cotidiano. RJ: DP\&A, 2003.

Pesquisa com o cotidiano. Educ. Soc., Campinas, v.28, n.98, p.73-95, jan./abr. 2007. Disponível em: <http://WwW.cedes.unicamp.br>. Acesso em: 22 jan. 2017.

(Org.). Currículos em redes. Curitiba: CRV, 2016.

GONÇALVES, Gláucia Signorelli de Queiroz. Inserção profissional de egressos do PIBID: desafios e aprendizagens no início da carreira. 2016. 243 f. Tese (Doutorado em Educação) - Programa de Pós-Graduação em Educação, Pontifícia Universidade Católica de São Paulo, São Paulo, 2016.

JOLY GOUVEIA, Aparecida. (1984). Notas a respeito das diferentes propostas metodológicas apresentadas. Cadernos de Pesquisa, [S.1.], v.49, p.67-70, maio 1984. Disponível em: <http://publicacoes.fcc.org.br/ojs/index.php/cp/article/view/1431 >. Acesso em: 13 nov. 2018. 
LUDKE, Menga; ANDRÉ, Marli. Pesquisa em educação: abordagens qualitativas. São Paulo: EPU, 1986.

MARQUES, Maria de Fátima Jeronimo. Mulheres/mães de crianças com deficiência: uma análise das dimensões de gênero na responsabilização das mulheres pelo cuidado direcionado aos membros da família. $2018.168 \mathrm{f}$. Tese (Doutorado em Educação) - Programa de Pós-Graduação em Educação, da Universidade Federal do Rio Grande do Norte, Natal, 2018.

MORIN, Edgar. Introdução ao pensamento Complexo. Porto Alegre: Sulina, 2007.

PAULON, Simone Mainieri; ROMAGNOLI, Roberta Carvalho. Pesquisa Intervenção e cartografia: melindres e meandros metodológicos. Estudos e Pesquisa em Psicologia, UERJ, Rio de Janeiro, ano.10, n.1, p.85-102, 2010.

PEREIRA, Rodnei. O desenvolvimento profissional de um grupo de coordenadoras pedagógicas iniciantes: movimentos e indícios de aprendizagem coletiva, a partir de uma pesquisa-formação.2017. $251 \mathrm{f}$. Tese (Doutorado em Educação) - Programa de Pós-Graduação em Educação, Pontifícia Universidade Católica de São Paulo, São Paulo, 2017.

SACRISTÁN, J. Gimeno. Currículo e diversidade cultural. In: Silva, T. T.; Moreira A. F. (Org.). Territórios contestados. Petrópolis: Vozes, 1995.p.xx-Xxx.

STAKE, Robert E. A arte da investigação com estudos de caso. Tradução do original inglês intitulado The Art of Case study Research. 4.ed. Lisboa: Fundação Calouste Gulbenkian, 2016. 
ANÁLISE DE PROSA ENREDADA NA PESQUISA COM OS COTIDIANOS: UM JEITO DE VER O CURRÍCULO E DIZER

RESUMO: Pesquisas qualitativas se caracterizam pela interpretação de dados da vivência, experiência e subjetividade dos praticantes. Isto implica na necessidade de reelaboração de novos procedimentos metodológicos e de análise que se adequem ao cenário de complexidade que se apresenta na atualidade. Com isto, este artigo apresenta o método de Análise de Prosa Enredado (APE), delieado em uma pesquisa com os cotidianos, focada na interação e triangulação das percepções e experiências registradas e na apresentação e enredamento dos resultados. A APE, apreende o caráter multidimensional, captando os diferentes sentidos de uma experiência vivida para a compreensão dos saberesfazeres, acompanhado dos seus significados.

PALAVRAS-CHAVES: Método de Análise, Pesquisa Qualitativa, Currículoformação.

PROSA ANALYSIS ENTITLED IN DAILY RESEARCH: A WAY TO SEE CURRICULUM AND SAY

ABSTRACT: Qualitative research is characterized by the interpretation of data on the experience, experience and subjectivity of practitioners. This implies the need for re-elaboration of new methodological and analysis procedures that fit the current scenario of complexity. With this, this paper presents the method of Entangled Prose Analysis (EPA), based on a daily research, focused on the interaction and triangulation of perceptions and experiences recorded and on the presentation and entanglement of results. The EPA apprehends the multidimensional character, capturing the different meanings of a lived experience for the understanding of the know-how, accompanied by their meanings.

KEYWORDS: Method of Analysis, Qualitative Research, Curriculum-training.

ANÁLISIS DE PROSA CON DERECHO A LA INVESTIGACIÓN DIARIA: UNA MANERA DE VER EL CURRÍCULO Y DECIR

RESUMEN: La investigación cualitativa se caracteriza por la interpretación de datos sobre la experiencia, la experiencia y la subjetividad de los profesionales. Esto implica la necesidad de reelaborar nuevos procedimientos metodológicos y de análisis que se ajusten al escenario actual de complejidad. Con esto, este documento presenta el método de Análisis de prosa enredada (EPA), basado en una investigación diaria, centrada en la interacción y triangulación de percepciones y experiencias registradas y en la presentación y el enredo de resultados. La EPA comprende el carácter multidimensional, capturando los diferentes significados de una experiencia vivida para la comprensión de los conocimientos, acompañados de sus significados.

PALABRAS CLAVE: Método de análisis, investigación cualitativa, formación curricular.

Submetido em Agosto de 2019

Aprovado em Dezembro de 2019

Revista Teias v. $20 \bullet$ n. 59 • out/dez $2019 \bullet$ Outras epistemologias e metodologias nas investigações sobre currículo 175 